\title{
El uso prolongado de anticonceptivos se asoció con un aumento reversible del riesgo de cáncer de cuello uterino
}

\author{
Prolongad use of oral contraceptives was associated with a reversible increase in cervical cancer risk
}

International Collaboration of Epidemiological Studies of Cervical Cancer. Lancet 2007; 370: 1609-21

\section{Objetivo}

Evaluar el riesgo de cáncer de cuello uterino (CCU) asociado al uso de anticonceptivos hormonales (AC).

\section{Búsqueda y selección de datos y pacientes}

PubMed, referencias de trabajos encontrados y comunicación con investigadores de estudios aún no publicados. Los criterios de inclusión planteados fueron: estudios de casos controles con más de 100 casos de cáncer invasivo ó 200 de CIN3, o cohortes prospectivas con más de 30 casos de CCU. Se excluyeron datos de mujeres histerectomizadas y con infección por virus de la inmunodeficiencia humana. Fueron incluidos estudios realizados en 26 países, la mitad de ellos no desarrollados. Se re-analizaron datos individuales de 24 estudios, tres de ellos multicéntricos. Correspondieron a 16.573 mujeres con CCU (11.170 con cáncer invasivo y 5.403 con cáncer in situ/CIN3) y 35.509 sin CCU.

\section{Evaluación de los factores de riesgo}

Características socioeconómicas, edad, paridad, conducta sexual, datos sobre rastreo de CCU, antecedentes de infección por el virus del papiloma humano (HPV) y uso de AC de cualquier clase.

\section{Medición de resultados principales}

Incidencia de CCU invasivo asociado al uso de AC, con estimación de los riesgos relativos, luego de un ajuste por todas las variables mencionadas.

\section{Resultados principales}

$\mathrm{La}$ incidencia de CCU invasivo entre las usadoras de AC orales se asoció al tiempo de uso con un riesgo relativo (RR) de 1,90 (IC95\% 1,69 a 2,13) para aquellas que lo hicieron durante más de cinco años vs. las que nunca los usaron; y retornando ese riesgo al de las no usadoras luego de diez años de suspendidos. El patrón observado fue similar para el cáncer invasivo y el carcinoma in situ, sin asociaciones significativas con las características de las mujeres.

\section{Conclusión}

El riesgo de CCU se vio incrementado en las usadoras de $\mathrm{AC}$ orales, desapareciendo el riesgo adicional luego de suspendidos.

Palabras clave: cáncer de cuello uterino, anticoncepción hormonal, revisión sistemática, $\mathrm{CIN}$, factores de riesgo.

Key words: cervical uterine cancers, hormonal contraception, systematic review, Key words:
risk factors.

Fuente de financiamiento: Cancer Research UK; IARC; UNDP/UNFPA/WHO/World Bank Special Program of Research, Development and Research Training in Human Reproduction. No refiere conflictos de interés.

\section{Comentario}

Al haber sólo incluido solo estudios observacionales y con los sesgos que esto implica, ésta prolija revisión sistemática habría obtenido evidencia más contundente si hubiera documentado un RR mayor a dos o tres'.

En los países en vías de desarrollo, el CCU es la segunda causa de muerte por cáncer en las mujeres, vinculado directamente con la exposición a hormonas sexuales, y mereciendo un lugar relevante en la agenda de investigación y en la evaluación de programas destinados a su control y reducción. Está difundida la importancia de su rastreo periódico con papanicolaou². En los últimos tiempos se ha profundizado el estudio sobre la etiología del CCU y su vínculo a la infección por HPV, incluyendo el desarrollo de nuevas tecnologías para su prevención.

La introducción de la píldora anticonceptiva y su gran aceptabilidad marcaron un momento histórico particular $\mathrm{y}$, desde la década del sesenta más de de 300 millones de mujeres en el mundo las han usado, estimándose hoy que más de 570 mil parejas la utilizan ${ }^{3}$. Dado su uso masivo, se ha estudiado masivamente su asociación con cánceres ginecológicos, habién- dose documentado en las "usadoras" una reducción en el riesgo de cáncer de ovario, un efecto probablemente nulo en el de mama y uno controvertido para el de CCU. El Instituto Nacional del Cáncer de EEUU sostiene que hay alguna evidencia de que el uso de la "píldora" durante más diez años puede estar relacionado mayor riesgo de desarrollar CCU. La información surge fundamentalmente de un análisis realizado por la Agencia Internacional para la Investigación sobre el Cáncer que halló mayor riesgo de CCU en utilizadoras de AC. La información disponible también sugeriría una reducción del riesgo con su suspensión, pero con evidencia insuficiente ${ }^{4}$.

\section{Conclusiones de la comentadora}

Cabe resaltar la magnitud de este estudio y la cautela en la interpretación de sus resultados, que sin duda refuerzan la importancia sostener el rastreo del $\mathrm{CCU}$ en la población femenina.

Vilda Discacciati [ Servicio de Medicina Familiar y Comunitaria del Hospital Italiano de Buenos Aires. vilda.discacciati@gmail.com ]

Discacciati V. El uso prolongado de anticonceptivos se asoció con un aumento reversible del riesgo de cáncer de cuello uterino. Evid. actual. práct. ambul; 10(6): 175, Nov-Dic.2007.Comentado de International Collaboration of Epidemiological Studies of Cervical Cancer. Cervical cancer and hormonal contraceptives: collaborative reanalysis of individual data for 16573 women with cervical cancer and 35509 women without cervical cancer from 24 epidemiological studies. Lancet 2007; 370: 1609-21. PMID: 17993361.

Referencias

1. LeLorier, J. Gregoire, G. Benhaddad,et al. Discrepancies between meta-analyses and subsequent large randomized, controlled trials. N Engl J Med. 1997;337 (8):536-42. 2. Yang BH, Bray FI, Parkin DM, Sellors JW, Zhang ZF. Cervical cancer as a priority for prevention in different world regions: an evaluation using years of life lost. Int J Cancer 2004; 109: 418-24

3. Burkman R., Schlesselman J, Zieman M, et al. Safety concerns and health benefits associated with oral contraception. American Journal of Obstetrics and Gynecology (2004) $190, \mathrm{~S} 5 \mathrm{e} 22$

4. Smith JS, Green J, de Gonzalez AB, et al. Cervical cancer and use of hormonal contraceptives: A systematic review. Lancet 2003; 361(9364):1159-1167. 